\title{
Use of Anthocyanin Profiles When Differentiating Individual Varietal Wines and Terroirs
}

\author{
Michal Kumšta, Pavel Pavloušek* and Pavel Kárník \\ Mendel University Brno, Faculty of Horticulture, Valtická 337, CZ-69144 Lednice na Moravě, \\ Czech Republic \\ Received: March 18, 2014 \\ Accepted: September 5, 2014
}

\begin{abstract}
Summary
In recent years, the importance of wine authenticity specification has significantly influenced the world wine market. Nowadays, the importance of terroir is emphasised worldwide. Also in European countries, where varietal wines are produced predominantly, the wine authenticity is given an increasing attention. Anthocyanin pigments represent an important group of phenolic substances that are used for the evaluation of wine authenticity. In this study, altogether 17 varietal red wines originating from the village Dolní Kounice (wine-growing region Moravia, Czech Republic) are evaluated. The evaluation involved three varieties, viz. Blaufränkisch (Lemberger), Saint Laurent and Blauer Portugieser as well as three terroirs named Karlov, Šibeniční vrch and Na Nivách. Anthocyanin pigments in varietal red wines were estimated by means of the HPLC method. Thanks to the application of chemometric methods, it was possible to determine the grapevine variety and to classify red wines on the basis of delphinidin-3-O-glucoside (DpGl), malvidin-3-O-glucoside $(\mathrm{MvGl})$ and delphinidin-3-O-acetylglucoside (DpGlAc) content. The terroir was discriminated on the basis of DpGl, MvGl and delphinidin-3-O-p-coumarylglucoside (DpGl$\mathrm{Cm})$ content.
\end{abstract}

Key words: anthocyanin, authenticity, grapevine varieties, HPLC, terroir, wine

\section{Introduction}

Grapevine (Vitis vinifera L.) is one of the most widespread cultural fruit crops in the world. Its planting locations are situated between $30^{\circ}$ and $50^{\circ}$ latitude in both northern and southern hemispheres. Wine, the main product made from grapes, is greatly influenced by its geographical origin.

As far as wine-making and wine marketing are concerned, the preservation of valuable properties and qualities of wine (e.g. genetic parameters, geographical origin, and/or unique wine-making technologies) is very important. The chemical composition of wine is therefore considered to be an essential part of its quality and authenticity (1).

Phenolic compounds are significant secondary plant metabolites from grape skin, seeds and pulp that are ex- tracted into wine (2). They form a group of secondary metabolites with various chemical structures and functions, and are produced during physiological growth of plants or in response to different forms of environmental stress (3). Phenolic compounds can be successfully used for the assessment of wine authenticity as they are characteristic for the type of wine and can provide information on its geographical origin (4). Two groups of flavonoids, the anthocyanins and flavanols, are particularly important for the quality of red wines.

Anthocyanins are very important compounds because they determine the colour of both grapes and red wine. As far as the red wine is concerned, colour can be regarded as one of the most important parameters. Anthocyanins can be defined as water-soluble vacuolar pigments that belong to the parent class of molecules called flavonoids. They are glycosides of anthocyanidins of which the 
most important are: pelargonidin, cyanidin, peonidin, delphinidin, petunidin and malvidin. Anthocyanins can conjugate with hydroxycinnamic acids ( $p$-coumaric or caffeic acid) and also with some other organic acids (e.g. acetic acid). In red wine made from different varieties of Vitis vinifera $\mathrm{L}$. one of the most important groups of anthocyanins are monomeric 3-O-diglucosides, especially malvidin-3-O-diglucoside and its derivatives (5).

The genome of each grapevine variety predetermines its typical profile of anthocyanins, by which individual grapevine cultivars can be differentiated (6-12) and thus the anthocyanin profile can be used to identify the grape variety used for making varietal wines (13). Consequently, it can also be used for the authentication of red wines, especially in the cases when the grapevine variety is displayed on the label (14).

Characteristics of wine are very closely related to its terroir. The wine origin has been and still is considered an indicator of wine quality and consumers often require information on the wine provenance (15). Generally, the differentiation and classification of wine samples on the basis of their chemical composition, geographical origin, variety and/or quality represent the basic methods of application of chemometry in oenology (16). The content and composition of anthocyanins in grapes and wine may be influenced by both environmental and genetic factors. Climatic factors (e.g. temperature, solar radiation, availability of water and its content in soil) influence significantly the content of anthocyanins in grapes (17-19).

Viticulture and wine-making represent an important part of our cultural heritage (20). The region of Dolní Kounice (Czech Republic) is a territory with a long-term tradition of growing grapevine varieties used for making red wine.

The aim of this study is to determine varietal authenticity and terroir of red wines based on their anthocyanin content and composition. Another objective of this study is to identify the anthocyanin pigments that characterize well not only the cultivated grapevine varieties but also the terroir of each wine sample.

\section{Materials and Methods}

\section{Samples and wine technology}

Evaluated wine samples were made from grapes of the following varieties: Blaufränkisch (seven samples), Blauer Portugieser (eight samples) and Saint Laurent (two samples). These red wines were produced in three different terroirs situated in the cadastre of the village Dolní Kounice, viz. Karlov (ten samples), Šibeniční vrch (five samples) and Na Nivách (two samples). The list of the evaluated wine samples is shown in Table 1 . The village Dolní Kounice is situated in the wine-growing region Moravia, sub-region Znojmo (Czech Republic). Grapes were produced by two growers in Dolní Kounice and red wine was made using an identical technology. Grapes were hand-picked into plastic boxes and immediately after the harvest, they were transported to a winery for processing.
Table 1. Grapevine varieties used in the study for the production of varietal wines

\begin{tabular}{lll}
\hline Grapevine variety & Year & Terroir \\
\hline Blaufränkisch & 1999 & Karlov \\
Blaufränkisch & 2001 & Karlov \\
Blaufränkisch & 2003 & Karlov \\
Blaufränkisch & 2006 & Karlov \\
Blaufränkisch & 2008 & Karlov \\
Blaufränkisch & 2007 & Na Nivách \\
Blaufränkisch & 2009 & Na Nivách \\
Blauer Portugieser & 2002 & Karlov \\
Blauer Portugieser & 2003 & Karlov \\
Blauer Portugieser & 2004 & Karlov \\
Blauer Portugieser & 2006 & Karlov \\
Blauer Portugieser & 2008 & Karlov \\
Blauer Portugieser & 2006 & Šibeniční vrch \\
Blauer Portugieser & 2008 & Šibeniční vrch \\
Blauer Portugieser & 2009 & Šibeniční vrch \\
Saint Laurent & 2004 & Šibeniční vrch \\
Saint Laurent & 2009 & Šibeniční vrch \\
\hline
\end{tabular}

The mash was macerated in stainless steel vinificators and regularly stirred. Within the first two days of maceration, the temperature was maintained between 28 and 30 ${ }^{\circ} \mathrm{C}$ and thereafter it was decreased to $25^{\circ} \mathrm{C}$. The malolactic fermentation took place after the end of alcoholic fermentation. After the end of fermentation, the wine was stored and aged in stainless steel containers for a period of 6 months. Wine aged for 6 months was analysed continuously. All analyses were done in triplicate.

\section{Estimation of individual anthocyanins}

To evaluate the anthocyanin fingerprint of wines originating from the village Dolní Kounice, the following 15 anthocyanins were used: delphinidin-3-O-glucoside (DpGl), cyanidin-3-O-glucoside (CyGl), petunidin-3-O-glucoside $(\mathrm{PtGl})$, peonidin-3-O-glucoside (PnGl), malvidin-3-O-glucoside (MvGl), delphinidin-3-O-acetylglucoside (DpGlAc), cyanidin-3-O-acetylglucoside (CyGlAc), petunidin-3-O-acetylglucoside (PtGlAc), peonidin-3-O-acetylglucoside (PnGlAc), malvidin-3-O-acetylglucoside (MvGlAc), delphinidin-3-O-p-coumarylglucoside (DpGlCm), cyanidin-3-O-p-coumarylglucoside $(\mathrm{CyGlCm})$, petunidin-3-O-p-coumarylglucoside $(\mathrm{PtGlCm})$, peonidin-3-O-p-coumarylglucoside (PnGlCm), and malvidin-3-O-p-coumarylglucoside (MvGl$\mathrm{Cm}$ ). Concentrations of individual anthocyanins were estimated using the previously reported method of analysis of anthocyanins in Czech red wine grape varieties (21).

Malvidin-3-O-glucoside (MvGl) was identified on the basis of a standard (Sigma-Aldrich, Prague, Czech Republic). Other anthocyanins separated on C18 column were identified on the basis of retention times reported by Peréz-Lamella et al. (11) and García-Beneytez et al. (22).

The reproducibility of the method was verified by spiking one sample from each series with malvidin-3-glu- 
coside. Recovery of the standards was in the range of (98102) \%. Retention times ranged from 26.23 to $26.41 \mathrm{~min}$ for MvGl. UV-VIS spectra were used to distinguish between $p$-coumarylglucoside and caffeoylglucoside derivatives of the anthocyanins.

Concentrations of anthocyanins for which standards were not available were determined by the calibration curve of MvGl. For the purpose of this work, the ratio of their peak areas is crucial, rather than their exact concentration. A typical chromatogram of anthocyanins is shown in Fig. 1.

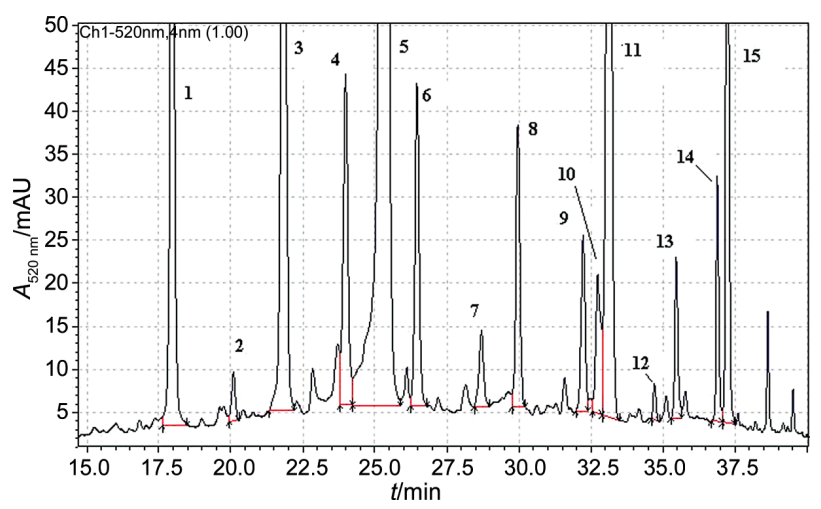

Fig. 1. Chromatogram of the Blauer Portugieser wine sample at $520 \mathrm{~nm}$. Peaks: $1=$ delphinidin-3-O-glucoside, $2=$ cyanidin-3-O-glucoside, $3=$ petunidin-3-O-glucoside, $4=$ peonidin-3-O-glucoside, $5=$ malvidin-3-O-glucoside, $6=$ delphinidin-3-O-acetylglucoside, $7=$ cyanidin-3-O-acetylglucoside, $8=$ petunidin-3-O-acetylglucoside, $9=$ peonidin-3-O-acetylglucoside, $10=$ malvidin-3- $O$-acetylglucoside, $11=$ delphinidin $-3-O-p$-coumarylglucoside, $12=$ cyanidin $-3-O-p$-coumarylglucoside, $13=$ petunidin-3-O- $p$-coumarylglucoside, $14=$ peonidin-3-O- $p$-coumarylglucoside, $15=$ malvidin-3-O- $p$-coumarylglucoside

\section{HPLC analysis}

The wine samples were centrifuged at $3000 \times g$ for $6 \mathrm{~min}$ and then diluted with $100 \mathrm{mmol} / \mathrm{L}$ of $\mathrm{HClO}$ (ratio 1:1). The chromatographic system Shimadzu LC-10A (Shimadzu, Kyoto, Japan) was used, which consisted of two pumps LC-10ADvp, a column thermostat with manual injection valve, a DAD detector SPD-M10Avp, and a PC running the chromatographic software. The chromatographic separations were performed using a column Alltech $^{\circledR}$ Alltima ${ }^{\mathrm{TM}}$ C18 (3 $\mu \mathrm{m}, 3 \times 150 \mathrm{~mm}$, Grace, Deerfield, IL, USA) equipped with a guard column $(3 \mathrm{~mm} \times 7.5 \mathrm{~mm}$ i.d.) filled with the same sorbent.

The temperature of separation was $60^{\circ} \mathrm{C}$. The gradient elution began with the flow rate of $0.6 \mathrm{~mL} / \mathrm{min}$ in the mobile phase A (15 mM of perchloric acid). The mobile phase B (5 mM perchloric acid, $10 \%$ methanol, and $50 \%$ of acetonitrile) was used as follows: $2 \%$ B for $0 \mathrm{~min}, 26 \%$ B for $20 \mathrm{~min}, 45 \%$ B for $30 \mathrm{~min}, 70 \%$ B for $35 \mathrm{~min}, 100 \%$ B for $37 \mathrm{~min}, 0 \% \mathrm{~B}$ for $38 \mathrm{~min}, 2 \% \mathrm{~B}$ for $40 \mathrm{~min}$ and $2 \% \mathrm{~B}$ for $45 \mathrm{~min}$. Acetonitrile $(\mathrm{ACN})$ and methanol $(\mathrm{MeOH})$ were of HPLC super gradient grade and perchloric acid was produced by Sigma-Aldrich (Prague, Czech Republic).

\section{Statistical data treatment}

The obtained data were processed according to the grapevine varieties and terroirs, and were expressed as mean values \pm standard deviations. The influence of a grapevine variety and terroir was determined using one-way analysis of variance (ANOVA) and the least significant difference (LSD) test at $\mathrm{p}<0.05$. The multivariate chemometric methods were used as a supervised learning technique for differentiation of wines to groups on the basis of the wine-growing region and finding markers which showed a significant discrimination value. When using a multivariate statistical analysis, it is necessary to designate suitable variables for classification of the samples first. In order to achieve this, the elimination of redundant variables using principal component analysis (PCA) was done. Principal components are orthogonal, and each principal component is a linear combination of the original variables. Canonical discriminant analysis (CDA) was subsequently performed using variables which showed higher significance in the PCA assessment.

\section{Results and Discussion}

\section{Concentrations of individual anthocyanins in varietal wines}

Concentrations of individual anthocyanins in varietal wines are presented in Table 2 . The highest average values were determined in red wines made from the variety Blauer Portugieser, lower in Blaufränkisch wine and the lowest in Saint Laurent. In Austrian red wine, however, the highest content of $\mathrm{MvGl}$ was detected in Blaufränkisch (23). In red wines, concentrations of monoglucosides were generally the highest. Increased concentrations of PtGl were found in varieties Saint Laurent $(7.0 \mathrm{mg} / \mathrm{L})$ and Blauer Portugieser $(6.3 \mathrm{mg} / \mathrm{L})$, while higher concentrations of PnGl were detected in Blaufränkisch $(3.8 \mathrm{~g} / \mathrm{L})$ and Saint Laurent (3.4 g/L). Papoušková et al. (24) also mentioned similar contents of PtGl and PnGl in red wines originating from the wine-growing region Bohemia. In individual varieties, concentrations of DpGl were nearly the same.

As far as other anthocyanins were concerned, concentrations of malvidin derivatives were also the highest. The highest concentrations of MvGlAc and MvGlCm were found in the variety Blauer Portugieser $(6.2$ and $5.0 \mathrm{mg} / \mathrm{L}$, respectively). On the other hand, the lowest concentrations of both aforementioned anthocyanins were estimated in the variety Blaufränkisch (1.9 and $3.6 \mathrm{mg} / \mathrm{L}$, respectively). A lower content of acylated glucosides in the variety Blaufränkisch was determined also by Papoušková et al. (24) in their study on Czech red wines.

Concentrations of acylated anthocyanins in varieties Saint Laurent and Blaufränkisch were significantly lower. Similar results were obtained also in a study of Austrian red wine from varieties Blaufränkisch and Saint Laurent (23). In the variety Blaufränkisch, the content of acylated anthocyanins was markedly lower than that of glycosidic anthocyanins. On the other hand, in varieties Saint Laurent and Blauer Portugieser the sums of acetylated, coumarylated and total anthocyanins were nearly the same. 
Table 2. Concentrations of individual anthocyanins in varietal wines

\begin{tabular}{lccc}
\hline \multicolumn{1}{c}{ Anthocyanin } & \multicolumn{1}{c}{$\gamma /(\mathrm{mg} / \mathrm{L})$} & Saint Laurent \\
\cline { 2 - 3 } Delphinidin-3-O-glucoside & Blaufränkisch & Blauer Portugieser & $4.7 \pm 2.3$ \\
Cyanidin-3-O-glucoside & $4.8 \pm 2.3$ & $4.7 \pm 2.4$ & $0.6 \pm 0.5$ \\
Petunidin-3-O-glucoside & $0.3 \pm 0.2$ & $0.4 \pm 0.2$ & $7.0 \pm 1.1$ \\
Peonidin-3-O-glucoside & $5.7 \pm 2.3$ & $6.3 \pm 1.6$ & $3.4 \pm 1.3$ \\
Malvidin-3-O-glucoside & $3.8 \pm 1.7$ & $2.7 \pm 1.1$ & $45.1 \pm 14.7$ \\
(monoglucosides anthocyanins) & $50.9 \pm 14.0$ & $51.4 \pm 8.4$ & $(60.9 \pm 11.8)^{\mathrm{b}}$ \\
Delphinidin-3-O-acetylglucoside & $(65.5 \pm 15.0)^{\mathrm{a}}$ & $0.8 \pm 0.2$ \\
Cyanidin-3-O-acetylglucoside & $0.3 \pm 0.2$ & $(65.4 \pm 5.1)^{\mathrm{a}}$ & $0.1 \pm 0.1$ \\
Petunidin-3-O-acetylglucoside & $0.13 \pm 0.06$ & $0.7 \pm 0.3$ & $0.9 \pm 0.3$ \\
Peonidin-3-O-acetylglucoside & $0.3 \pm 0.2$ & $0.18 \pm 0.08$ & $1.1 \pm 1.0$ \\
Malvidin-3-O-acetylglucoside & $0.3 \pm 0.2$ & $0.8 \pm 0.4$ & $5.8 \pm 3.2$ \\
$\Sigma$ (acetylated anthocyanins) & $1.9 \pm 1.1$ & $0.7 \pm 0.3$ & $(8.6 \pm 4.9)^{\mathrm{b}}$ \\
Delphinidin-3-O-p-coumarylglucoside & $(3.0 \pm 1.5)^{\mathrm{a}}$ & $6.2 \pm 1.4$ & $0.7 \pm 0.6$ \\
Cyanidin-3-O- $p$-coumarylglucoside & $0.5 \pm 0.4$ & $(8.5 \pm 2.0)^{\mathrm{b}}$ & $0.6 \pm 0.4$ \\
Petunidin-3-O-p-coumarylglucoside & $0.3 \pm 0.1$ & $0.6 \pm 0.3$ & $0.8 \pm 0.2$ \\
Peonidin-3-O-p-coumaryl glucoside & $0.5 \pm 0.2$ & $0.4 \pm 0.2$ & $1.2 \pm 0.4$ \\
Malvidin-3-O-p-coumarylglucoside & $0.9 \pm 0.3$ & $0.6 \pm 0.2$ & $4.6 \pm 0.3$ \\
$\Sigma$ (coumarylated anthocyanins) & $3.6 \pm 1.7$ & $1.0 \pm 0.3$ & $(7.9 \pm 0.6)^{\mathrm{b}}$ \\
$\Sigma$ (acylated anthocyanins) & $(5.8 \pm 2.4)^{\mathrm{a}}$ & $5.0 \pm 1.3$ & $(16.5 \pm 4.4)^{\mathrm{b}}$ \\
\hline
\end{tabular}

The results are expressed in $\mathrm{mg} / \mathrm{L}$ of malvidin-3-O-glucoside (MvGl). The values followed by different letters in the same row are significantly different by LSD test at $\mathrm{p}<0.05$

\section{Concentrations of individual anthocyanins in wine samples with different terroirs}

Concentrations of individual anthocyanins in varietal wines according to different terroirs are presented in Table 3. Similarly as in the case of individual varieties, MvGl was the dominant anthocyanin also in this study. As far as the concentration of $\mathrm{MvGl}$ was concerned, there were significant differences among individual terroirs. The highest concentration of MvGl was found in the terroir $\mathrm{Na}$ Nivách. Of the group of monoglucosides, PtGl and DpGl occurred in significant amounts in the terroir Karlov. In contradistinction to varieties, the concentration of DpGl can also be significantly influenced by the terroir. As far as other anthocyanins were concerned, the most frequent were malvidin derivatives (similarly as in individual varieties). A significantly higher concentration of MvGlAc was recorded in the wine originating from the terroir Šibeniční vrch, while the highest concentration of $\mathrm{MvGlCm}$ was observed in the terroir Karlov.

The highest sums of monoglucoside anthocyanins, acetylated anthocyanins and coumarylated anthocyanins were detected in wines made from grapes produced in terroirs Na Nivách, Šibeniční vrch and Karlov, respectively.

\section{Chemometric differentiation of wine samples on the basis of individual varieties and terroirs}

The principal component analysis (PCA) is a multivariate method that quantitatively analyses the dependent variables. It was used to analyse all variables of all anthocyanins. The first two components represented $58.6 \%$ of total variance ( $\mathrm{PC} 1=35.8 \%, \mathrm{PC} 2=22.8 \%$ ). On the basis of the PCA method, variables for the canonical discriminant analysis were selected. The following anthocyanins were eliminated from further assessment: PnGl, CyGlAc and $\mathrm{MvGlCm}$. These compounds turned out to be insignificant for wine differentiation using the PCA method. In order to increase the discrimination value obtained by means of the PCA method, the geographical origin of wine and the varietal authenticity were verified by means of canonical discriminant analysis (CDA). This method included only those variables which proved to have a high significance for the differentiation of geographical and varietal origin using the PCA method.

Canonical discriminant analysis is a dimension-reduction technique related to PCA and canonical correlation. Given a nominal classification of variables together with several interval variables, the CDA method derives those canonical variables that explain the inter-class variation in the same way as the principal components summarize total variation (25). The CDA was therefore used for the determination of anthocyanins which were also the most important for the wine differentiation on the basis of terroir and of grapevine variety in this study.

The variance of the differentiation of grapevine variety was $96.1 \%$ for CVA1 and $3.9 \%$ for CVA2 (i.e. $100.0 \%$ of total variation). The differences between grape varieties were significant. The standardized canonical discriminant functions for varietal differentiation are presented in Table 4.

As it can be seen in Fig. 2, the obtained results indicate that CVA1 was positively correlated with DpGl, DpGlAc and PnGlCm, and negatively with PtGlAc, PnGlAc, CyGl- 
Table 3. Concentrations of individual anthocyanins in samples of varietal wine originating from individual terroirs

\begin{tabular}{|c|c|c|c|}
\hline \multirow{2}{*}{ Anthocyanin } & \multicolumn{3}{|c|}{$\gamma /(\mathrm{mg} / \mathrm{L})$} \\
\hline & Karlov & Na Nivách & Šibeniční vrch \\
\hline Delphinidin-3-O-glucoside & $5.7 \pm 1.8$ & $2.2 \pm 1.5$ & $3.7 \pm 2.2$ \\
\hline Cyanidin-3-O-glucoside & $0.4 \pm 0.1$ & $0.2 \pm 0.1$ & $0.4 \pm 0.4$ \\
\hline Petunidin-3-O-glucoside & $6.4 \pm 2.1$ & $4.6 \pm 0.6$ & $6.2 \pm 1.5$ \\
\hline Peonidin-3-O-glucoside & $3.7 \pm 1.5$ & $2.9 \pm 1.0$ & $2.4 \pm 1.1$ \\
\hline Malvidin-3-O-glucoside & $47.4 \pm 9.4$ & $63.6 \pm 7.6$ & $51.3 \pm 12.8$ \\
\hline$\Sigma$ (monoglucosides anthocyanins) & $(63.6 \pm 11.6)^{a}$ & $(73.6 \pm 4.4)^{\mathrm{b}}$ & $(64.1 \pm 8.7)^{\mathrm{a}}$ \\
\hline Delphinidin-3-O-acetylglucoside & $0.4 \pm 0.3$ & $0.19 \pm 0.09$ & $0.8 \pm 0.4$ \\
\hline Cyanidin-3-O-acetylglucoside & $0.2 \pm 0.7$ & $0.14 \pm 0.02$ & $0.1 \pm 0.1$ \\
\hline Petunidin-3-O-acetylglucoside & $0.5 \pm 0.4$ & $0.2 \pm 0.2$ & $1.0 \pm 0.3$ \\
\hline Peonidin-3-O-acetylglucoside & $0.4 \pm 0.3$ & $0.4 \pm 0.1$ & $0.9 \pm 0.6$ \\
\hline Malvidin-3-O-acetylglucoside & $3.9 \pm 2.7$ & $2.7 \pm 0.5$ & $6.0 \pm 2.0$ \\
\hline$\Sigma$ (acetylated anthocyanins) & $(5.4 \pm 3.3)^{\mathrm{b}}$ & $(3.6 \pm 0.9)^{\mathrm{a}}$ & $(8.9 \pm 3.1)^{c}$ \\
\hline Delphinidin-3-O-p-coumarylglucoside & $0.7 \pm 0.4$ & $0.2 \pm 0.1$ & $0.5 \pm 0.4$ \\
\hline Cyanidin-3-O- $p$-coumarylglucoside & $0.41 \pm 0.05$ & $0.20 \pm 0.07$ & $0.5 \pm 0.3$ \\
\hline Petunidin-3-O- $p$-coumarylglucoside & $0.6 \pm 0.2$ & $0.4 \pm 0.2$ & $0.7 \pm 0.2$ \\
\hline Peonidin-3-O-p-coumarylglucoside & $1.0 \pm 0.4$ & $0.93 \pm 0.05$ & $1.0 \pm 0.3$ \\
\hline Malvidin-3-O- $p$-coumarylglucoside & $4.7 \pm 1.9$ & $3.6 \pm 0.4$ & $4.0 \pm 0.7$ \\
\hline$\Sigma$ (coumarylated anthocyanins) & $(7.4 \pm 2.5)^{\mathrm{b}}$ & $(5.4 \pm 0.8)^{\mathrm{a}}$ & $(6.6 \pm 1.3)^{\mathrm{b}}$ \\
\hline$\Sigma$ (acylated anthocyanins) & $(12.8 \pm 5.2)^{\mathrm{b}}$ & $(9.04 \pm 0.08)^{\mathrm{a}}$ & $(15.6 \pm 3.4)^{c}$ \\
\hline
\end{tabular}

The results are expressed in $\mathrm{mg} / \mathrm{L}$ of malvidin-3-O-glucoside (MvGl). Values followed by different letters in the same row are significantly different by LSD test at $\mathrm{p}<0.05$

Table 4. Standardized canonical discriminant functions used for grapevine variety-based differentiation

\begin{tabular}{lcc}
\hline \multirow{2}{*}{\multicolumn{1}{c}{ Anthocyanin }} & \multicolumn{2}{c}{ Discriminant function } \\
\cline { 2 - 3 } & CVA1 & CVA2 \\
\hline Delphinidin-3-O-glucoside & 10.824 & 5.554 \\
Cyanidin-3-O-glucoside & -2.644 & -1.769 \\
Petunidin-3-O-glucoside & -4.078 & -3.727 \\
Malvidin-3-O-glucoside & -0.528 & 4.020 \\
Delphinidin-3-O-acetylglucoside & 29.783 & 1.702 \\
Petunidin-3-O-acetylglucoside & -18.813 & 0.765 \\
Peonidin-3-O-acetylglucoside & -14.653 & -1.800 \\
Malvidin-3-O-acetylglucoside & -5.949 & 1.136 \\
Delphinidin-3-O-p-coumarylglucoside & -7.513 & 1.303 \\
Cyanidin-3-O-p-coumarylglucoside & -9.566 & 0.368 \\
Petunidin-3-O- $p$-coumarylglucoside & -2.617 & 0.610 \\
Peonidin-3-O- $p$-coumarylglucoside & 10.884 & -0.872 \\
\hline Eigenvalue & 206.511 & 8.340 \\
Variance/\% & 96.1 & 3.9 \\
\hline
\end{tabular}

$\mathrm{Cm}$ and DpGlCm. CVA2 was positively correlated with DpGl and MvGl, and negatively with PtGl and PnGlAc. CVA1 enabled good separation of the variety Blaufränkisch from Blauer Portugieser and Saint Laurent. This means that the variety Blaufränkisch can be well characterised on the basis of the presence of anthocyanins DpGl, DpGlAc and PnGlCm. On the other hand, CVA2 separated the variety Blauer Portugieser from varieties Blaufrän-

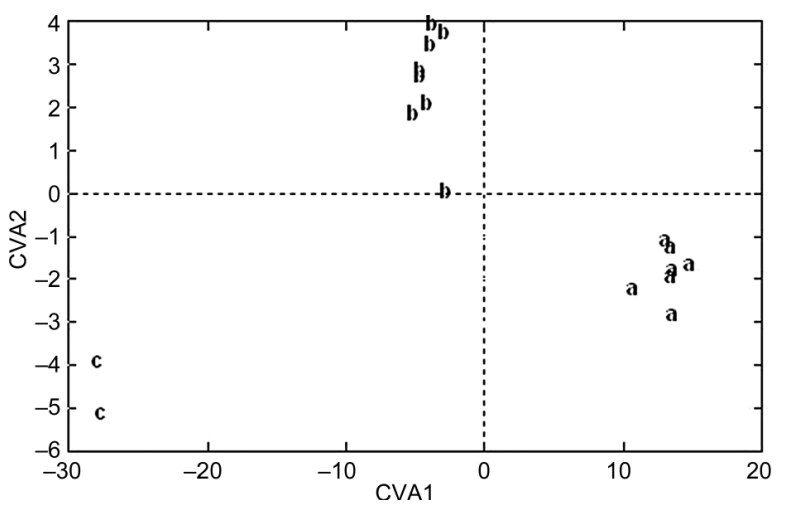

Fig. 2. Results of canonical variate analysis of wines obtained from different grapevine varieties ( $a=$ Blaufränkisch, $b=$ Blauer Portugieser, c=Saint Laurent) for the first (CVA1, variance 3.9 $\%$ ) and the second (CVA2, variance $96.1 \%$ ) variate

kisch and Saint Laurent. This means that the variety Blauer Portugieser can be characterised very well on the basis of the profile of anthocyanin pigments DpGl and MvGl.

As far as the separation of varietal red wines was concerned, concentrations of anthocyanins DpGl, MvGl, PtGl, DpGlAc, PnGlCm and PnGlAc represented the most important discrimination parameters. MvGl showed to be an important discrimination parameter in samples of red wine originating from Austria (23), Canary Islands (26) and Greece (7). DpGL also belonged to discrimination compounds that enabled the identification of not only Hungarian red wines (24), but also of red wines originating from some other European countries $(7,27,28)$. Among 
the group of acylated anthocyanins, DpGlAc was a good discrimination parameter of individual grapevine varieties in a study on Spanish wines (29). It was proven in the studies evaluating the varietal authenticity that PnGl can also be used as a discrimination parameter $(23,26)$. In our study, this anthocyanin was eliminated already after the application of PCA.

The explained canonical variance used for the differentiation of terroir represents $98.5 \%$ for CVA1 and $1.5 \%$ for CVA2. The differences between individual regions were significant (Wilks' lambda value was 0.0072 at the value of $\mathrm{p}=0.01$ ). The Wilks' lambda value near zero indicates a good discrimination function of the individual CVAs. Standardized canonical discriminant functions for terroir-based differentiation are presented in Table 5.

Table 5. Standardized canonical discriminant functions used for terroir-based differentiation

\begin{tabular}{lcc}
\hline \multirow{2}{*}{\multicolumn{1}{c}{ Anthocyanin }} & \multicolumn{2}{c}{ Discriminant function } \\
\cline { 2 - 3 } & CVA1 & CVA2 \\
\hline Delphinidin-3-O-glucoside & 14.275 & -0.704 \\
Cyanidin-3-O-glucoside & -4.926 & 1.753 \\
Petunidin-3-O-glucoside & -7.328 & -0.220 \\
Malvidin-3-O-glucoside & 3.107 & 0.173 \\
Delphinidin-3-O-acetylglucoside & -3.343 & 3.950 \\
Petunidin-3-O-acetylglucoside & 1.032 & -3.393 \\
Peonidin-3-O-acetylglucoside & -0.178 & -1.622 \\
Malvidin-3-O-acetylglucoside & 1.618 & -0.591 \\
Delphinidin-3-O-p-coumarylglucoside & 2.638 & -0.894 \\
Cyanidin-3-O- $p$-coumarylglucoside & 1.821 & -2.186 \\
Petunidin-3-O- $p$-coumarylglucoside & -3.302 & 0.567 \\
Peonidin-3-O- $p$-coumarylglucoside & 2.162 & 1.498 \\
\hline Eigenvalue & 68.28 & 1.02 \\
Variance/\% & 98.5 & 1.5 \\
\hline
\end{tabular}

As it can be seen in Fig. 3, the obtained results indicate that CVA1 was positively correlated with DpGl, MvGl and DpGlCm, and negatively with CyGl, PtGl and Dp-

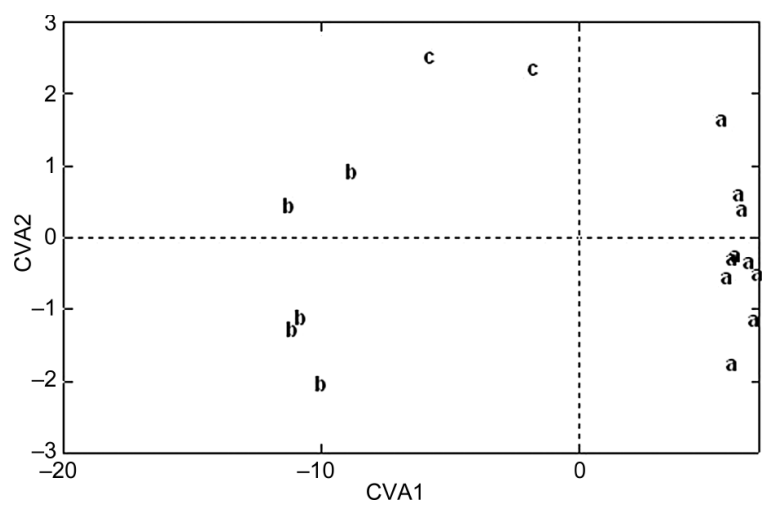

Fig. 3. Results of canonical variate analysis for the first (CVA1, variance $98.5 \%$ ) and second (CVA2, variance $1.5 \%$ ) variate of

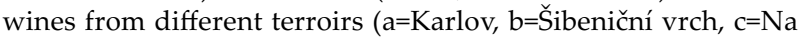
Nivách)
GlAc. CVA2 was positively correlated with DpGlAc and CyGl, and negatively with PtGlAc and CyGlCm. CVA1 separated very distinctively the vineyard site Karlov from other two vineyard sites (i.e. Šibeniční vrch and $\mathrm{Na}$ Nivách). Wines originating from the vineyard site Karlov were characterised very well on the basis of the concentrations of anthocyanins DpGl, MvGl and DpGlCm. When using CVA2, it was not possible to discriminate wine samples originating from vineyards Šibeniční vrch and $\mathrm{Na}$ Nivách. Monoglucosides DpGl, MvGl and a derivative of $p$-coumaric acid, DpGlCm, could therefore be taken into account as the main discrimination parameters of red wine samples originating from different vineyard sites on the basis of the profile of anthocyanin pigments.

In the wine samples from the village of Dolní Kounice it is therefore possible to consider anthocyanins MvGl, DpG and DpGlCm as the main discrimination factors applicable for the differentiation of individual terroirs within a certain region. The suitability of using $\mathrm{MvGl}$ as discriminant factor was also corroborated in the studies of terroirs in Greece (7), Argentina (30) and Brazil (31). Similarly as in our study, the suitability of using DpGl as a discriminant factor was demonstrated only in a study dealing with the evaluation of Greek red wines (7). It is possible to conclude that phenolic compounds may be considered as chemical markers in studies on the authenticity of the variety and the geographic origin of wine (30). This was also corroborated by the results obtained within the framework of this study on red wine.

In the previous studies of the phenylpropanoid pathway $(7,32-34)$, it was demonstrated that environmental factors also influence the biosynthesis of anthocyanins. Monoglucosidic forms of anthocyanins represent the final product of the phenylpropanoid pathway (35). This means that terroir is a contributing factor to the formation of anthocyanins.

\section{Conclusions}

The results of this study of anthocyanin fingerprinting of wine originating from the village Dolní Kounice show that it was possible to identify and separate not only grapevine varieties but also the terroir of wine. Very good results were obtained when trying to characterise the varieties Blaufränkisch and Blauer Portugieser on the basis of anthocyanins DpGl, DpGlAc, PnGlCm and DpGl, MvGl, respectively. It was found that the applicability of anthocyanin fingerprinting in the studies of the differentiation of wines from the viewpoint of terroir was very good. The terroir Karlov can be quite explicitly identified on the basis of DpGl, MvGl and DpGlCm. This study on Moravian red wines therefore demonstrates the suitability of application of anthocyanin profiles in differentiation and identification of individual varieties and terroirs.

\section{References}

1. L. Muccillo, A. Gambuti, L. Frusciante, M. Iorizzo, L. Moio, K. Raieta et al., Biochemical features of native red wines and genetic diversity of the corresp onding grape varieties from Campania region, Food Chem. 143 (2014) 506-513. http://dx.doi.org/10.1016/j.foodchem.2013.07.133 
2. G.L. La Torre, M. Saitta, F. Vilasi, T. Pellicano, G. Dugo, Direct determination of phenolic compounds in Sicilian wines by liquid chromatography with PDA and MS detection, Food Chem. 94 (2006) 640-650. http://dx.doi.org/10.1016/j.foodchem.2005.02.007

3. M. Naczk, F. Shahidi, Extraction and analysis of phenolics in food, J. Chromatogr. A, 1054 (2004) 95-111. http://dx.doi.org/10.1016/S0021-9673(04)01409-8

4. A. Andreu-Navarro, P. Russo, M.P. Aguilar-Caballos, J.M. Fernández-Romero, A. Gómez-Hens, Usefulness of terbium-sensitised luminescence detection for chemometric classification of wines by their content in phenolic compounds, Food Chem. 124 (2011) 1753-1759.

http://dx.doi.org/10.1016/j.foodchem.2010.08.014

5. F. He, N.N. Liang, L. Mu, Q.H. Pan, J. Wang, M.J. Reeves, C.Q. Duan, Anthocyanins and their variation in red wines I. Monomeric anthocyanins and their color expression, Molecules, 17 (2012) 1571-1601. http://dx.doi.org/10.3390/molecules17021571

6. G. González-Neves, J. Franco, L. Barreiro, G. Gil, M. Moutounet, A. Carbonneau, Varietal differentiation of Tannat, Cabernet-Sauvignon and Merlot grapes and wines according to their anthocyanic composition, Eur. Food Res. Technol. 225 (2007) 111-117. http://dx.doi.org/10.1007/s00217-006-0388-8

7. D. Makris, S. Kallithraka, A. Mamalos, Differentiation of young red wines based on cultivar and geographical origin with application of chemometrics of principal polyphenolic constituents, Talanta, 70 (2006) 1143-1152. http://dx.doi.org/10.1016/j.talanta.2006.03.024

8. J.M. Ryan, E. Revilla, Anthocyanin composition of Cabernet Sauvignon and Tempranillo grapes at different stages of ripening, J. Agric. Food Chem. 51 (2003) 3372-3378. http://dx.doi.org/10.1021/jf020849u

9. J. Burns, W. Mullen, N. Landrault, P.L. Teissedre, M.E.J. Lean, A. Crozier, Variations in the profile and content of anthocyanins in wines made from Cabernet Sauvignon and hybrid grapes, J. Agric. Food Chem. 50 (2002) 4096-4102. http://dx.doi.org/10.1021/jf011233s

10. R. Eder, S. Wendelin, J. Barna, Classification of red wine cultivars by means of anthocyanin analysis. 1st report: Application of multivariate statistical methods for differentiation of grape samples, Mitt. Kloster. 44 (1994) 201-212 (in German).

11. C. Pérez-Lamela, M.S. García-Falcón, J. Simal-Gándara, I. Orriols-Fernández, Influence of grape variety, vine system and enological treatments on the colour stability of young red wines, Food Chem. 101 (2007) 601-606. http://dx.doi.org/10.1016/j.foodchem.2006.02.020

12. M. Figueiredo-González, E. Martínez-Carballo, B. CanchoGrande, J.L. Santiago, M.C. Martínez, J. Simal-Gándara, Pattern recognition of three Vitis vinifera L. red grapes varieties based on anthocyanin and flavonol profiles, with correlations between their biosynthesis pathways, Food Chem. 130 (2012) 9-19.

http://dx.doi.org/10.1016/j.foodchem.2011.06.006

13. H. Otteneder, R. Marx, M. Zimmer, Analysis of the anthocyanin composition of Cabernet Sauvignon and Portugieser wines provides an objective assessment of the grape varieties, Aust. J. Grape Wine Res. 10 (2004) 3-7. http://dx.doi.org/10.1111/j.1755-0238.2004.tb00002.x

14. Q. Zhao, C.Q. Duan, J. Wang, Anthocyanins profile of grape berries of Vitis amurensis, its hybrids and their wines, Int. J. Mol. Sci. 11 (2010) 2212-2228. http://dx.doi.org/10.3390/ijms11052212

15. T. Atkin, R. Johnson, Appellation as an indicator of quality, Int. J. Wine Bus. Res. 22 (2010) 42-61. http://dx.doi.org/10.1108/17511061011035198

16. A. de Villiers, P. Majek, F. Lynen, A. Crouch, H. Lauer, P. Sandra, Classification of South African red and white ac- cording to grape variety based on the non-coloured phenolic content, Eur. Food Res. Technol. 221 (2005) 520-528. http://dx.doi.org/10.1007/s00217-005-1169-5

17. S. D. Castellarin, M.A. Matthews, G. Di Gaspero, G.A. Gambetta, Water deficits accelerate ripening and induce changes in gene expression regulating flavonoid biosynthesis in grape berries, Planta, 227 (2007) 101-112. http://dx.doi.org/10.1007/s00425-007-0598-8

18. J.M. Tarara, J. Lee, S.E. Spayd, C.F. Scagel, Berry temperature and solar radiation alter acylation, proportion, and concentration of anthocyanin in Merlot grapes, Am. J. Enol. Vitic. 59 (2008) 235-247.

19. G. Gonzales-Neves, G. Gil, G. Favre, M. Ferrer, Influence of grape composition and winemaking on the anthocyanin composition of red wines of Tannat, Int. J. Food Sci. Technol. 47 (2012) 900-909. http://dx.doi.org/10.1111/j.1365-2621.2011.02920.x

20. P.T. Tarr, M.L. Dreyer, M. Athanas, M. Shahgholi, K. Saarloos, T.P. Second, A metabolomics based approach for understanding the influence of terroir in Vitis vinifera L., Metabolomics, 9 (2013) 170-177.

http://dx.doi.org/10.1007/s11306-013-0497-x

21. J. Balík, M. Kumšta, O. Rop, Comparison of anthocyanins present in grapes of Vitis vinifera L. varieties and interspecific hybrids grown in the Czech Republic, Chem. Pap. 67 (2013) 1285-1292.

http://dx.doi.org/10.2478/s11696-013-0378-9

22. E. García-Beneytez, F. Cabello, E. Revilla, Analysis of grape and wine anthocyanins by HPLC-MS, J. Agric. Food Chem. 51 (2003) 5622-5629. http://dx.doi.org/10.1021/jf0302207

23. R. Eder, S. Wendelin, J. Barna, Classification of red wines based on anthocyanin analysis, XXIV World Congress of Vine and Wine and the 79th General Assembly of the OIV: World Viticulture and Markets, Variety and Specialty: Oenology Meets the Demands of the Market, Vol. 1, Mainz, Germany (1999) 149-156 (in German).

24. B. Papoušková, P. Bednář, K. Hron, J. Stávek, J. Balík, R. Myjavcová et al., Advanced liquid chromatography/mass spectrometry profilig of anthocyanins in relation to set of red wine varieties certified in Czech Republic, J. Chromatogr. A, 42 (2011) 7581-7591. http://dx.doi.org/10.1016/j.chroma.2011.07.027

25. R. Moreno-Rojas, P.J. Sánchez-Segarra, F. Cámara-Martos, M.A. Amaro-López, Multivariate analysis techniques as tools for categorization of southern Spanish cheeses: Nutritional composition and mineral content, Eur. Food Res. Technol 231 (2010) 841-851. http://dx.doi.org/10.1007/s00217-010-1338-z

26. J.P. Pérez-Trujilo, Z. Hernández, F.J. Pólez-Bellido, I. Hermosín-Gutiérrez, Characteristic phenolic composition of singlecultivar red wines of the Canary Islands (Spain), J. Agric. Food Chem. 59 (2011) 6150-6164. http://dx.doi.org/10.1021/jf200881s

27. M. Figueiredo-González, B. Cancho-Grande, J. Simal-Gándara, Garnacha Tintorera-based sweet wines: Chromatic properties and global phenolic composition by means of UV-Vis spectrophotometry, Food Chem. 140 (2013) 217-224. http://dx.doi.org/10.1016/j.foodchem.2013.02.055

28. M. Pour Nikfardjam, L. Márk, P. Avar, M. Figler, R. Ohmacht, Polyphenols, anthocyanins, and trans-resveratrol in red wines from the Hungarian Villány region, Food Chem. 98 (2006) 453-462.

http://dx.doi.org/10.1016/j.foodchem.2005.06.014

29. M.J. Noriega, A. Casp, Anthocyanin characterization of young red wines from Appellation of Origin Navarra (Spain), J. Int. Sci. Vigne Vin, 41 (2007) 111-119. 
30. M. Fanzone, A. Peňa-Neira, V. Jofré, M. Assof, F. Zamora, Phenolic characterization of Malbec wines from Mendoza province (Argentina), J. Agric. Food Chem. 58 (2010) 23882397.

http://dx.doi.org/10.1021/jf903690v

31. R.H. Soares de Andrade, L. Samara do Nascimento, G.E. Pereira, F. Hallwass, A.P.S. Paim, Anthocyanic composition of Brazilian red wines and use of HPLC-UV-Vis associated to chemometrics to distinguish wines from different regions, Microchem. J. 110 (2013) 256-262.

http://dx.doi.org/10.1016/j.microc.2013.04.003

32. S.E. Spayd, J.M. Tarara, D.L. Mee, J.C. Ferguson, Separation of sunlight and temperature effects on the composition of $\mathrm{Vi}$ tis vinifera cv. Merlot berries, Am. J. Enol. Vitic. 53 (2002) $171-182$.
33. K. Bindon, P. Dry, B. Loveys, Influence of partial rootzone drying on the composition and accumulation of anthocyanins in grape berries (Vitis vinifera cv. Cabernet Sauvignon), Aust. J. Grape Wine Res. 14 (2008) 91-103. http://dx.doi.org/10.1111/j.1755-0238.2008.00009.x

34. R. Flamini, F. Mattivi, M. De Rosso, P. Arapitsas, L. Bavaresco, Advanced knowledge of three important classes of grape phenolics: Anthocyanins, stilbenes and flavonols, Int. J. Mol. Sci. 14 (2013) 19651-19669. http://dx.doi.org/10.3390/ijms141019651

35. E. Petrussa, E. Braidot, M. Zancani, C. Peresson, A. Bertolini, S. Patui, A. Vianello, Plant flavonoids - Biosynthesis, transport and involvement in stress response, Int. J. Mol. Sci. 14 (2013) 14950-14973.

http://dx.doi.org/10.3390/ijms140714950 